above Gamboa; another would be built at Gamboa, where the Chagres first meets the line of the canal; the thir would be built near the mouth of the Chagres on the Atlantic; and the fourth at the mouth of the Rio Grande on the Pacific. The impounding dam the Rio Grande on the Pacific. The impounding dam
at Gatun would be solid and ischarged by a spillway or barrage.

Now, the gates in the sluice dams at Alhajuela an Gamboa would normally be left open, and the basin back of them empty. But in times of flood the gates would be partly closed and the dams allowe to fill with the excess, their joint capacity, and in fact the capacity of the Gamboa dam alone, being far more than enough to take care of any single flood. When the flood had passed, the sluice gates at Gamboa would allow the impounded floo waters to discharge slow ly into the canal, half of the water flowing towar the Pacific and the other half toward the Atlantic, the amount being regulate so that it would not produce sluice gates in the barrages at the Atlantic and Pacific terminals of the canal, would be so regulate as to terminals of the canal, would be so regulate as to
maintain at all times a predetermine depth of wate in the central and terminal lakes.

II. The Lake and Lock Project: The feature of Mr. Bates's plan which distinguishes it sharply from the plans that have precede it, is the free use which he makes of the system of canalization by means of impounde artificial lakes. The metho is not a new one as applied to the Panama problem, for it was suggested during the earlier studies of the question by the French engineer, Godin de Lapinay; and, later, it figure in the emergency plans for the quick completion of the canal, which were drawn up by the French when it became apparent that they were unable to put through a canal at sea level. No one, how ever, has attempted the canalization of the Chagres and Rio Grande rivers on the bold scale that is propose by Mr. Bates. Of the three alternative plans which he offers, we have selected the one known as Plan B, which contemplates the use of four locks with two levels, and the formation of three large fresh-wate lakes. The central lake (Lake Chagres) is formed by the construction of a dam at Gatun which serves to hold the water at a level of 62.5 feet above the mea sea level. In the Chagres lake the channel would be excavate along the bottom to a depth of 40 feet and a bottom width of 150 feet. The waters would back up the Chagres valley for a distance, measure along the ship channel, of about 20.6 miles. From this point th canal would be excavated, at the same surface level of plus 62.5 , through the foothills and the main range of the Culebra divide for a distance of 10.5 miles to stretch from Gatun to Pedro Miguel, about 31.1 miles in length, would constitute the summit level, 20.6 miles of it consisting of lake navigation, and 10.5 miles of it consisting of lake navigation, and 10.5 miles
only consisting of canal proper, bounde by nearly parallel barks. The remainder of the canal, both on the Pacific and Atlantic sides, would be forme by cre ating two large terminal lakes with their surface hel at an elevation from 26.5 to 33.5 feet above mean sea level, and dredging out the ship channel to a depth of 40 feet and a bottom widt of 150 feet.

These two great terminal lakes are, perhaps, the most attractive feature in Mr. Bates's plan; for they not only serve to greatly reduce the amount of necessary excavation, but by flooding the swampy land lying adjacent to the canal termini they assist in the improvement of sanitary conditions. By referring to the accompanying maps showing the terminal harbors, it will be seen that the topography of the countr lends itself admirably to the construction of these dams, for in each case the rivers, as they approac the ocean, pass through a natural depression of incon siderable width formed in the ridges that exten approximately parallel with the coast line.

III. Terminal Harbors: The provision of terminal harbors and safe entrances is an important feature in any great ship canal such as this, and in the plans under consideration it has receive particular attention. As stipulate by the act authorizing the construction of the canal, these harbors should provide secure military and naval bases. By reference to our map of the Pacific terminus, it will be seen that break waters are designe whose arms are to inclose the whole harbor of Panama and Ia Boca, and extend from the mainland to the islands that face the entrance. As these breakwaters would he built of the rock excavate from the canal, they would represent but little additional cost over that which would be involved if the excavate material were waste at sea. The location of the canal is changed from the curved line of the old location to a straight line which extends from the upper end of the terminal Panama Lake, straigh out through the harbor entrance, as shown on our map. It passes through locks which will be built adjacent to the barrage on good rock foundation in the Ancon-Sosa Saddle; while to the southwest, beyond stretch of rising ground, is the dike, less than a mile in length, which serves to impound the waters of Lake Panama. At the Atlantic end a similar provision of breakwaters serves to form a sheltere harbor at the entrance to the canal, and advantage is taken of coast by placing the canal entrance, the barrage, and the locks in one depression, and the impounding dike in the narrow valley of the lower Chagres. In this harbor also the alignment of the canal will be straightened and its length proportionately reduced. The cre ation of these two harbors, coupled with the large fresh-water lakes adjoining them, will provide such extende facilities for the safe harboring of ships, both of the navy and the mercantile marine, that it is not possible for any increase in future canal navigaion to cause congestion at these points.

IV. Disposal of Excavated Material: One of the greatest problems, if not the most important, is the disposal of the enormous amount of excavated material, chiefly from the Culebra cut. In the plans under consideration, Mr. Bates brings the bulk of the Culebra excavation down to the Pacific coast, and dumps it inside the big harbor forme by the breakwaters above referre to, until a large area of the harbor, several square miles in extent, has been fille in and brought well above high-tide level. Upon the site thus formed he would build a greater Panama, providing a splendid and healthy site for the great growth which must take place in this important terminal city. At the Atlantic terminus he advocates the abandonment of the old town of Colon, and the creation of a new town, to be called Balboa, on the easterly slope of the hill that flanks on the west the locks and barrage at the canal entrance. From a naval standpoint the harbor facilities, as thus presented, are very attractive, inasmuch as fresh-water naval stations can be formed back of the hills of the coastal ridges, and the protection of the ships' bottoms against marine growth, which is one of the advantages of a fresh-water harbor, gives to this feature of the plans a ecided military value.

V. Water Suprly and Lockage: It is claimed, and with much show of reason, that the important question

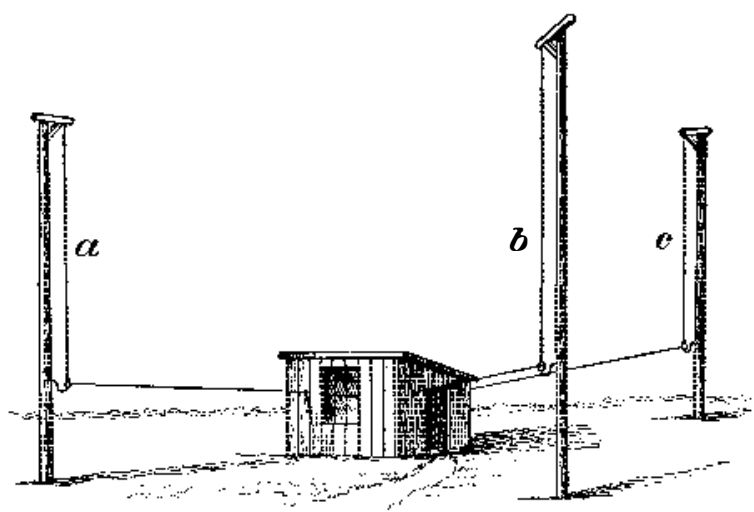

ARRANGEMENT OF THE AERIALS FOR DIRECTING THE MESSAGES.

of water supply for lockage purposes, in view of the great increase in vessel dimensions, has never receive Mr. Bates considers that with the great growth in tonnage passing through the canal, which is certain to occur as the years go by, the mere creation of a single storage basin in the upper Chagres valley would not provide, especially in the dry season, a safe reserve for lockage. This is shown by the following figures: The three dry months of the dryest year in which gagings have been taken at Bohio show an average discharge of 742 cubic feet per second. By moving the impounding am from Bohio to Gatun, the waters of the Trinidad and Gatuncillo become contributory to the water supply, and the average flow in a dry season for the same months of these rivers, added to that at Bohio, shows that there would be never less sumed that the early traffic, when the canal is open, will amount to $7,279,000$ tons, the lockage for which would require a flow of 306 cubic feet per second. Evaporation from the lakes will account for 280 cubic feet per second, leakage will equal 257 cubic feet per second, making a total of 843 cubic feet per second that is necessary to maintain the canal at its proper levels. This will give a surplus for the three dry months of at least 157 cubic feet per second. Now, if we eliminate waters coming in from the lower Chagres tributaries, it can be seen that instead of a surplus there would be a shortage of lockage water. Hence the importance of the inclusion of the drainage of the two tributaries of the Chagres above referred to in the total available supply of lockage water. When we consider the possibilities of storage in the navigated lakes and canal, it is evident that the transit capacity is far more than is likely to be require for many generations to come.

VI. Time of Transit: The most surprising claim made on behalf of the lake and lock project is, that the time of transit through the canal would be considerably less than if it were built at sea level. This is based on the fact that large ships in passing through a canal inclosed by banks, must procee at a much slower speed than when they are steaming through a channel dredged in a navigable lake. It is claime that the average speed through a sea-leve canal could not exceed, safely, 4.23 miles per hour, including the time lost at the tidal lock on the Pacific, whereas in the lake and lock canal a speed of 7.08 miles per hour would be practicable. The higher speed in the waterway would more than offset the time lost in passing through the extra locks, so that the total transit time for the sea-level canal would be 12.3 hours, whereas for the lake and lock canal the time would be only 8.89 hours. The slow speed necessary in a canal inclose by banks is due to the fact that, if a certain speed is exceeded, a ship, should it swerve from its course, has a tendency to swing, with accelerated turning movement, into either bank before the rudder can control it. This is due to the fact that the water cannot escape freely around the hull in a constricted channel as it can in a lake channel, where wer few feet of a ship's hull is in the channel and the body of the ship is in a wide expanse of

Vil. Time and Cost of Construction: The erection of the impounding dikes and the barrages and the locks would be simplified by the fact that a good indurate clay rock exists at the selected sites, and that no difficulty would be experienced with the founda. tions. The creation of the inland lakes greatly reduces the total amount of excavation, which is brought down to a total of $118,430,000$ cubic yards, as compare with an estimate total of $300,000,000$ cubic yards for a sealevel canal. The estimate total cost is $\$ 125,000,000$; and allowing from a year to a year and a half for designing the special plant that would be require and placing it upon the ground, it is estimated that the canal would be opene for navigation by the year 1915 .

That the author of the above-described plan has the courage of his convictions is shown by the fact that he is prepare to put in a bid for constructing the whole canal at the rate of $\$ 3,125,000$ per mile, reckoning the canal as 40 miles in length, to be completed under a guarantee in eight years.

\section{BRAUN'S NEW METHOD OF DIRECTING WIRELESS MESSAGES}

The first attempts toward directing wireless telegraph messages were made by William Marconi some little time before he hal evolved his aerial wire system. His apparatus consiste of a small induction coil fitted with a battery to supply the initial energy, a key to break up the current into the alphabetic code, and a Righi oscillator for radiating the energy in the form of electric waves. In this case the oscillator was mounted in the focal line of a cylindrical parabolic reflector the length and opening of which was double the length of the wave emitted from the oscillator. This arrangement permitted the waves to be concentrated into a beam which could be projecte in any desire direction. The receiver consiste of a resonator forme of two plates of metal with a detector connected to and interposed between them; this was likewise place in the focus of a similar parabolic reflector the opening of which was oppositely disposed to that of the transmitting reflector. With this combination it was possible to concentrate the waves into a beam, but the scheme was not practicable, at least over any considerable distance, since the oscillator and resonator systems were so limite in size that the emitte wave lacke the requisite amount of energy to be of rcial service.

In the Scientific American of October 7, 1905, the writer describe a system for directing electric waves invente by Alessandro Artour, of Italy, who by an ingenious arrangement of the spark-gap spheres an aerial wires was enable to obtain circularly and elliptically polarize electric radiations, thus forming rays capable of being propagate in any direction and without the use of grids to reflect them. Considerable success has attende these experiments, messages having been transmittel over 300 kilometers, while an other station less than 100 kilometers distant and outside the effective line could not receive them.

Prof. Ferdinand Braun, of the Strasburg Institute, has recently brought out a new method for directing wireless messages in which it is not necessary to bunch the waves into a ray. His method is based on the theory of wave intensification and rarefaction by interference. Thus, assuming that two aerial radiating wires are tune to the same period of oscillation and are energized by currents from the same oscillator, it should not be difficult to obtain interference phenomena provide the oscillations set up in one of the aerials have a phase difference of a small fraction of a second from those of the other.

While the time difference require between the two series of oscillations is exceedingly small, yet it is no easy to tune both oscillations to the same period and yet differentiate the time sufficiently to produce a lag necessary to bring about the desired interference.

This was finally accomplished in the laboratory by throwing the two series of oscillations out of phase by means of an inductance inserted in one of them 
near the spark gap. The results on this small scale seemed to agree fairly well with the theory on which it was based and it was decided by the investigator to try out the system under conditions that prevail in practice, i.e., using loftier air wires and grounding the complementary terminal of the spark gap.

The place selected for making the out-of-door tests was the polygon military drill grounds at Strasburg. Three different stations were set up within this limited space, one for sending and the other two for receiving. At the transmitting station, insteal of the usual aerial wire there were three radiating wires arranged at equidistant points from each other around the building and several meters from it. The aerials were suspende from the tops of their respective masts in the usual manner. The lower ends of these wires led into the building which housed the transmitting apparatus. The lower terminals of all the aerials were connected to one side of the spark gap, the opposite side of the latter being connected to the earth in the ordinary way. Now, when the disruptive discharge took place, the aerials $a b c$ were energized by the oscillations thus set up, but while the oscillations in the aerials $b c$ were exactly in step, those in a lagge slightly, due to the aded inductance near the spark gap; yet the values of inductance and capacity remaine identical, so that the length of the waves emanating from each remained constant. When all the aerials were emitting waves, those radiate by $a$ would, in virtue of the fact that it was out of phase with $b$ and $c$, set up an interference, with the result that an electrical shadow was cast in a direction at right angles to the plane of the aerial wires $b$ and $c$, and hence the radiation of waves in that direction was a minimum. Oppositely, if the oscillations in the aerial $a$ were made to take place in advance of those occurring in $b$ and $c$, provide the difference in time was rightly proportioned, then a wave more or less amplifie would result and its propagation would be in the direction previously stated while the shadow due to the interference of the waves on $b$ and $c$ was projected from the rear of $a$.

In this system of amplifying the waves in one direc tion and diminishing them in another, the greatest difficulty seems to grow out of the fact that it is of the utmost importance to time the period of oscillation with absolute precision; and when it is stated that this difference of phase amounts to approximately only one ten-millionth of a second, it will be seen that the ajustments of the co-efficients are of an extremely delicate nature. From Prof. Braun's experience with high-frequency oscillations he concludes that the difference in time between the phases of the aerials can be adjusted to within one two-hundred-millionth part of a second, or more popularly expressed it would amount to a difference of only one second in six years.

Two or three years ago the scheme was tried to form a parabolic reflector of gigantic proportions by arranging a number of aerial wires around a radiating aerial wire so that the latter would be in the focal line. This arrangement faile to produce the desired results, since the wires thus placed permitted much of the energy to be lost through dispersion. Prof. Braun investigate the reflection of wires on a scale sufficiently large to show its utter impracticability. He employe waves having a length of 120 meters and place the radiating aerial wire a distance of 30 meters or a quarter of a wave-length from the reflecting wires, which had an opening

By utilizing the three-wire system the large and complicated reflecting-wire scheme is eliminated, the distance of transmission is increase and, what is equally advantageous, it is possible to direct the messages in any one of six directions. Without removing a single connection the waves can be sent in either one of two directions by merely increasing or decreasing the frequency of the oscillations in $a$ so that these will be a ten-millionth of a second faster or slower than the currents that surge through $b$ and $c$. By changing the relative phase values of $a b c$, it is obvious that any of six different predetermined directions can be obtained at pleasure.

In the recent experiments made by Prof. Braun and his co-workers, while messages were being transmitte in one direction and receive by a station in line with it, a second receiving station at right angles to the line of propagation, though much nearer the transmitter than the first, was not affected.

Should it prove of advantage to transmit in more than six directions, five wires would be used, with the result that any one of ten stations, assuming they were locate at equidistant points about the transmitting station, could then be communicated with to the exclusion of all the others. The maximum distance covere in these preliminary trials was 1.3 kilometers; it is stated, however, that a commercial test is to be made at an early date.

On her return trip the Cunard turbine steamer "Carmania" steame on an average $17 \frac{1}{2}$ ' knots. During the whole voyage she met with persistent head winds. Her best day's steaming was 420 knots.

\section{THE SOLDIER-MOUNTAINEERS OF ITALY.}

It is difficult for us who have practically no frontiers at all to realize the conditions that obtain in the Old World, where comparatively small nations a join one another like the squares on a chessboard; th boundary line in many cases being purely imaginary, and beyond it commencing a new language and a new country, with totally different manners and customs. In many places, however-as, for example, at th Franco-Spanish frontier, and also between Italy and Switzerland, and Switzerland and Austria-the boundary between the natio of snow-clad mountains; and as invasion is to be feared even across the lofty passes (did not the might Napoleon himself cross the great Alps with an army, carrying dismay and terror into Austria?) there ar in European armies whole regiments that are carefully trained to fight literally "above the clouds." In other words, they combine the strength, endurance, and skil of the most intrepid Swiss Alpine guide with the ordinary profession of soldier. And there is nothing more interesting than to watch the maneuvers of these soldier-mountaineers-say, at Andermatt in Switze land, or Aosta on the Italian side of the Great St. Bernard.

Andermatt is a village lying over 4,000 feet above the lower end of Lake Lucerne, and here will be found the headquarters of the Swiss Alpine troops, whose maneuvers should be seen to be believed, so darin are they, and so astonishing the spectacles presente by long files of panting men, small as flies on the wall of some terrible precipice, yet dragging literally inch by inch some big field gun up a tremendous slope by means of pulleys and hemp cables. One notices that these infantrymen are provide with alpenstocks an coils of silk rope, as well as snowshoes, ski, and othe paraphernalia which we usually associate with the pleasure tourist in the high Alps-say at Chamounix, Zermatt, Grindenwald, or some other popular climbin center of the "Playground of Europe."

Their signaling is one from rock to rock by mean of huge painte linen isks, held upon the outstretche arms of the signaler. The wounded are carried easel-backe chair, fastene on the stalwart backs of their comrades. It is a fact that these troops maneuver literally "above the clouds"; and there is no mor impressive spectacle than a Sunday morning service in some little icy recess at nine or ten thousand feet, when the chaplain of the regiment mounts into a rude portable pulpit, and discourses upon the wonders of the Almighty to the assembled soldiers who are shiver ing in their furs, even though it be July or August. At one side of the pulpit are the members of the band and these play the hymns which reverberate throug the awful desolations of glacier and snow-peak, gloomy gorge, and sky-piercing pyramid.

The Italian Alpine troops are in some ways still more remarkable. Indeed, I doubt whether as a whole any army in the world goes through such curious the House of Savoy-H. R. H. the Count of Turinplunging into the River Arno at Florence at the head of his hussars, and the entire regiment swam across, each trooper with his arm about his traine charger neck. I have also seen the same high commanding officer ride his regiment straight into the sea at Via reggio; for it is necessary to accustom both cavalrymen and the mounts to the negotiation of deep water, against the time they may find themselves in an enemy's country with all the bridges destroyed.

As one leaves the Swiss town of Martigny, and be gins the long, toilsome ascent of the Great St. Bernar Mountain, one looks forward to reaching the Italian frontier at Aosta, by way of the far-famed hospice of St. Bernard, whose dogs and monks are a household wor the world over. At the side of the lake near the hospice, a few stones mark the Italian frontier. A we descend, the scenery assumes a soft Italian character, and the awful desolation of Mount St. Bernar figes place to walnut groves, chestnuts,
fig trees. Soon the southern spurs of Monte Rosa appear; and just before we enter Aosta, the pass is alive with soldiers. Some of them are marching on ski over the frozen snow; others again are glissading down steep slopes.

The little town lies about 2,000 feet above sea leve and is surrounde by ancient walls flanke with tow10,000-foot Becca di Nona, and the Mont Emilius, 11,670 feet. Aosta is an admirable climbing center, not only because the Italian Alpine troops have their headquarters here, but also because various Alpine clubs have built refuges and cut paths up colossal mountains, which would otherwise be inaccessible to any livi

Aosta is filled with military barracks, and in these as well as in the open squares one sees embryo soldier mountaineers in the making. Here is a party of re cruits, half extended on the ground leaning on their
left arms, while their right are high in the air, raising

and lowering big weights. This exercise is to develop the muscles of arm and back for the long, tedious climb over high, snowy mountains, and across slippery glaciers abounding in treacherous crevasses, which may be covered by an insidious layer of snow, liable to give way at any moment after a burst of sunshine.

One great idea is to accustom these men to hauling and pulling; for while Alpine troops are on the march it is obvious they cannot take any pack animals with them, much less commissariat wagons. Each man is heavily burdened with rifle, bayonet, two or three hundred rounds of ball cartridge; several days' rations, snowshoes or ski, blankets, and other items, which in themselves make up a serious load, to be carried up great mountains by paths which to the uninitiated look only fit for goats.

And yet, on top of all this equipment the Italian so'dier-mountaineer is required, on occasion, to take over parts of machine-guns, portable telephones, camp utensils, and other articles. Down below, in Aosta, pack-mules were loade up in trains with the barrels of mountain howitzers; also with their wheels, separately, and certain shelter-tents, picks and shovels, and other implements. These hardy beasts are led as high selves venture up wild icy precipices of the Alps where not even a mule could fin foothold. At a certain not even a mule could find foothold. At a certain
point, therefore, the pack-mules are unloade and led lown again to Aosta, after their loads have been distributed among the hardy troops, who shoulder their added burdens with a smile, grip the ashen shaft of their alpenstocks, and scramble up the precipices and almost perpendicular crags the best way they can. Sometimes the most daring among them will reach a point of vantage, and then lower a rope up which his fellows are to climb one by one. These soldier-mountaineers are the most wonderful rope-climbers I have ever seen in action. It is no small matter for a man to climb up a rope at all in the ordinary way; then what must it be when he is loaded with nearly sixty pounds' weight of equipment? Down at the barracks in the town, all recruits go through regular exercises in rope climbing, bearing the whole of their equipage. The idea of the whole training is that one day it may be necessary to meet an enemy equally daring and skillful among these wild Alpine solitudes. For the French also have Alpine troops, and one may see these indulging in similar strange tactics on the colossal Mont Blanc itself. It is a fact that lightly-equipped French infantrymen, led by young officers, have gained the very summit of the giant of the Alps, which, as
everyone knows, is n, arly 16,000 feet high and is

All these soldier-moustaineers are crack shots; and it is difficult to see how one of the forts held by them amid the great granite bowlders and terrible pinnacles and spires of the Great St. Bernard could ever be force by an enemy in the face of these troops, who would act as scouts, crawling up precipices, and planting themselves on wi'd and seemingly inaccessible spots, whence they wou pour an invisible fire which nothing could withstanu. These Alpine troops, when scouting or reconnoitering in the mountains, use a curious kind of rifle-rest, formed by three alpenstocks and one of the pillows they use at night when they sleep in the snow. For, strange as it may seem, these ble to put up tents, but merely altitues do not trouvast snow-drifts, and line these with waterproof sheets and blankets, and there sleep amid dreary Alpine deso lations as comfortably as though they were down on earth in a comfortable city bed.

The life of the men is magnificently healthy and exhilarating, as may be seen by the bright eyes, rosy cheeks, and clear complexions of a party of scouts that come glissading like lightning down the slopes of frozen snow on their long curving ski, guided and supported by the alpenstock. The troops also carry Arctic sleages for the transport of their "wounded"; and sometimes realistic demonstrations are given, when one or several men will lie at full length on these sledges and be dragge or glissader over glacier and snowfield.

Much has been said and written about aerial warfare-I mean between airships provided with explosives. This may be $i$ ream of the distant future, but nothing is more practicable than a clash between the Alpine troops of say France and Italy in the tremendous mountains of the Haute Savoie, many thousands of feet above the level of the sea. And just consider what that warfare would be! No cavalry, of course, no wheeled artillery; but only busy soldiermountaineers clambering by ropes up dizzy precipices, hoping to pour their fire from a height.

Officers, too, shouting commands through megaphones, or using the field telephones from rock to rock, and encouraging their men to carry up the mountain guns and open fire with these until the vast silent 